\title{
OPERATIONAL USE OF SPACEBORNE LIDAR DATASETS
}

\author{
Franco Marenco*, Gemma Halloran and Mary Forsythe \\ Satellite Applications, Met Office, United Kingdom \\ *Email: franco.marenco@metoffice.gov.uk
}

\begin{abstract}
The Met Office plans to use space lidar datasets from CALIPSO, CATS, Aeolus and EarthCARE operationally in near real time (NRT), for the detection of aerosols. The first step is the development of NRT imagery for nowcasting of volcanic events, air quality, and mineral dust episodes. Model verification and possibly assimilation will be explored. Assimilation trials of Aeolus winds are also planned. Here we will present our first in-house imagery and our operational requirements.
\end{abstract}

\section{INTRODUCTION}

Lidar is useful in identifying atmospheric aerosol layers such as volcanic ash, mineral dust, smoke from biomass burning, polluted layers, etc. As it senses the vertical structure of the atmosphere, lidar is also useful in defining the layer height, a quantity that is otherwise weakly constrained using passive satellite imagery.

The CALIPSO mission has been very successful [1], having been in orbit since 2006 and having long exceeded its nominal lifetime. It is difficult to predict when it will fail, but this could happen at very short notice. Moreover, since 2015 the CATS instrument has been installed on the International Space Station (ISS), and it intended to operate in orbit for up to 3 years [2]. A followon mission is being considered at the moment.

In the near future, the launch of two missions from ESA are expected: ADM-Aeolus is mainly intended for measuring wind speed, but will provide an aerosol product, and EarthCARE is a mission that specifically targets clouds and aerosols [3,4].

Current lidar imagery from CALIPSO and CATS is available directly on NASA web portals, and it is assumed that in the future ESA will provide it in a similar manner for its missions. These products are probably the best quality that can be achieved. However, level 1 data are available online several days (sometimes several weeks) after their acquisition. Unfortunately these delays make the use of the imagery unlikely for nowcasting or operational data assimilation.

It is however also possible to set up the reception of near real-time (NRT) products. These come as data files, and then imagery has to be produced inhouse. The data may also not contain the full spectrum of information, being at a lower data level (e.g. L1 instead of L2).

Coverage is another issue as these sensors have a narrow swath and their repeat cycles vary between 3 and 25 days; moreover the CATS/ISS system only covers the $52 \mathrm{~S}-52 \mathrm{~N}$ latitude band (see Table 1).

At the Met Office we are currently considering such products, having made contact with the instrument scientists and having started the reception of the NRT products. At the time of writing this abstract, we are in the process of developing in-house imagery. This imagery will be discussed in this presentation, together with a first assessment of the operational requirements.

\section{REQUIREMENTS}

NRT lidar products could be used in the London VAAC (Volcanic Ash Advisory Centre), based at the Met Office: they can assist in the identification of volcanic ash layers and help assign their height in the atmosphere. This is not possible at the moment using the datasets disseminated online, due to the delay between the acquisition of the measurements and the data availability. The layer height determined by lidar can in principle be used to initialize the Numerical Atmospheric dispersion Modeling Environment (NAME) dispersion model, used for volcanic ash predictions. NRT products are also useful to identify the layer height in air quality and mineral 
Table 1. Spaceborne lidar missions considered.

\begin{tabular}{|l|l|l|l|l|l|}
\hline Mission & $\begin{array}{l}\text { Expected } \\
\text { Lifetime }\end{array}$ & Coverage & $\begin{array}{l}\text { Repeat } \\
\text { cycle }\end{array}$ & $\begin{array}{l}\text { Expected } \\
\text { timeliness }\end{array}$ & $\begin{array}{l}\text { Product } \\
\text { name }\end{array}$ \\
\hline CALIPSO & $2006-?$ & $82 \mathrm{~S}-82 \mathrm{~N}$ & $16 \mathrm{~d}$ & $12-72 \mathrm{~h}$ & L1.5 expedited \\
\hline CATS & $2015-2018$ & $52 \mathrm{~S}-52 \mathrm{~N}$ & $3 \mathrm{~d}$ & $6 \mathrm{~h}$ & $\mathrm{~L} 1$ \\
\hline Aeolus & $2017-2020$ & $83 \mathrm{~S}-83 \mathrm{~N}$ & $7 \mathrm{~d}$ & $3 \mathrm{~h}$ & L2A \\
\hline EarthCARE & $2018-2021$ & $83 \mathrm{~S}-83 \mathrm{~N}$ & $25 \mathrm{~d}$ & $\begin{array}{l}60 \% \text { data } \\
\text { within 6 } \mathrm{h}\end{array}$ & L2A, L2B \\
\hline
\end{tabular}

dust events.

In the future we could consider testing the data assimilation of lidar datasets to constrain the dust layer height in weather prediction models. The Met Office Unified Model (MetUM) in its Global configuration is run operationally four times a day for the prediction of mineral dust concentration. Currently, MODIS AOD is the only assimilated information on aerosol load, and therefore layer height is fully determined by the model. There will however be limitations with this, as overpasses at a given location are infrequent.

Moreover, lidar signals are noisy, and simulating the measured signal may be tricky as they depend upon all aerosol types at once, and are strongly influenced by the cloud field. Possibly, the verification and assimilation work could be experimented using the layer base and top height information given in the lidar datasets to help constrain the vertical distribution.

\section{SYNERGY WITH THE GROUND- BASED LIDAR NETWORK}

The Met Office is setting up an operational network with 10 Raymetrics ground-based lidars. The main aim is the detection and monitoring of volcanic events, but the instruments may also help fill other requirements, along the lines discussed above. The imagery from these instruments is currently available internally within 15 minutes of acquisition. Current quicklooks do not show calibrated products or retrieved quantities; thus, they only give a qualitative image of the atmospheric structure. In a successive phase, however, calibrated signals could be delivered and/or retrieved products could be inferred. Such datasets could then be used for model validation and/or data assimilation.

\section{DOPPLER WIND LIDAR}

ADM Aeolus requires a separate discussion, as this mission's main objective is to provide horizontal line of sight (HLOS) winds for numerical weather prediction (NWP). The Met Office will be exploring the potential of this new instrument.

The Met Office is part of the Aeolus cal/val team and will therefore gain early access to the data products. Monitoring of their quality and coherence with other global wind observations will be put in place and maintained through the lifetime of the mission. For this, NWP model fields will be used as a source of comparison (observations minus background) using established methods for the evaluation of large volumes of observations. The objective here is to identify data quality issues, to produce a reliable observation operator, capable of simulating the Aeolus data from model fields, and to assess biases and uncertainties.

When we have completed this analysis, and as long as the data is of sufficient quality, we intend to trial for assimilation in the Met Office global model and assess where the data provides most benefit and measure the impact of Aeolus on the forecast quality. 
Airborne cal/val activities of ADM/Aeolus, using the FAAM BAe-146 research aircraft, are also contemplated, with the aim of

- a direct comparison of measured winds;

- an evaluation of wind variability and issues of scale;

- insight of the effect of heterogeneities in the aerosols and cloud fields on the derived winds;

- studies on scene classification.

Detailed planning of the Aeolus cal/val plans will be established after launch, and pending the availability of sufficient funding.

\section{CONCLUDING REMARKS}

The project of using spaceborne lidar datasets operationally at the Met Office is in its infancy. This presentation will discuss our requirements, show first imagery products, and describe our plans for the cal/val of Aeolus.

\section{ACKNOWLEDGEMENTS}

Thanks to the CALIPSO, CATS, Aeolus and EarthCARE teams at NASA and ESA for the provision of spaceborne lidar datasets and the openness in discussing requirements.

\section{References}

Numbered in the order they appear in the text, with brackets. Example of references:

[1] Winker, D.M., J. Pelon, J.A. Coakley, S.A. Ackerman, R.J. Charlson, P.R. Colarco, P. Flamant, Q. Fu, R.M. Hoff, C. Kittaka*, T.L. Kubar, H. Le Treut, M.P. McCormick, G. Mégie*, L. Poole, K. Powell, C. Trepte, M.A. Vaughan, and B.A. Wielicki, 2010: The CALIPSO Mission: A Global 3D View of Aerosols and Clouds, Bull. Am. Meteorol. Soc. 91, 1211-1228.

[2] Yorks, J.E., M.J. McGill, S.P. Palm, D.L. Hlavka, P.A. Selmer, E P. Nowottnick, M.A. Vaughan, S.D. Rodier, and W.D. Hart, 2016: An overview of the CATS level 1 processing algorithms and data products, Geophys. Res. Lett. 43, 4632-4639.

[3] Endemann, M., Dubock, P., Ingmann, P., Wimmer, R., Morancais, D., \& Demuth, D., 2004: The Adm-Aeolus Mission - the First Wind-Lidar in Space, in Proceedings of the 22nd International Laser Radar Conference (ILRC 2004) held in Matera, Italy, 12-16 July 2004, edited by G. Pappalardo and A. Amodeo, European Space Agency ESA SP-561, Paris, 953pp.

[4] A.J. Illingworth, H.W. Barker, A. Beljaars, M. Ceccaldi, H. Chepfer, N. Clerbaux, J. Cole, J. Delanoë, C. Domenech, D.P. Donovan, S. Fukuda, M. Hirakata, R.J. Hogan, A. Huenerbein, P. Kollias, T. Kubota, T. Nakajima, T.Y. Nakajima, T. Nishizawa, Y. Ohno, H. Okamoto, R. Oki, K. Sato, M. Satoh, M.W. Shephard, A. Velázquez-Blázquez, U. Wandinger, T. Wehr, G.-J. van Zadelhoff, 2015: The EarthCARE Satellite: The Next Step Forward in Global Measurements of Clouds, Aerosols, Precipitation, and Radiation, Bull. Am. Meteorol. Soc. 96, 1311-1332. 